\title{
MEMBANGUN EDUGAME “ BABY ZOO PUZZLE” BERBASIS ANDROID DENGAN GAME AGENT IMPLEMENTASI FINITE STATE MACHINE
}

\author{
Ahmad Rofiq Hakim ${ }^{1)}$, Reza Andrea ${ }^{2)}$, Devian Antoni ${ }^{3)}$ \\ ${ }^{1}$ Sistem Informasi, STMIK Widya Cipta Dharma \\ ${ }^{2,3}$ Teknik Informatika, STMIK Widya Cipta Dharma \\ $1,2,3$ J1. M. Yamin No.25, Samarinda, 75123 \\ E-mail : rofiq_93@yahoo.com ${ }^{1)}$,reza@bbirdesign.com ${ }^{2)}$,devian.anthony@gmail.com ${ }^{3)}$
}

\begin{abstract}
ABSTRAK
Dalam pembuatan edugame "baby zoo puzzle" berbasis android dengan game agent implementasi finite state machine. Edugame "baby zoo puzzle" menggunakan algoritma pengacakan posisi pada potongan-potongan puzzle penggunaan algoritma pengacakan posisi agar potongan puzzle tidak mudah dihapal dan pada game agent menggunakan metode finite state machine (FSM), game agent akan memberikan notifikasi atau pemberitahuan pada para pemain. Metode Finite State Machine perancangan sistem control yang menggambarkan prinsip kerja sistem dengan menggunakan tiga hal : state (keadaan), event (kejadian), action (aksi) yang digunakan kedalam game agent dapat memberikan aksi dan reaksi kepada pemain pada saat permainan dimainkan. Hasil dari pembuatan edugame"baby zoo puzzle" berupa .Apk dan .Exe yang dapat di jalan platform android dan PC, edugame "baby zoo puzzle" berbasis android dapat dimainkan untuk semua umur dari anak-anak hingga dewasa.
\end{abstract}

Kata Kunci: Edugame, Puzzle, Android, Game agent, Finite State Machine

\section{PENDAHULUAN}

Permainan merupakan salah satu yang menarik untuk dikembangkan. Pemanfaatan dan penggunaan game edukasi puzzle dapat menunjang proses pembelajaran. Pembelajaran dengan menggunakan game edukasi puzzle dapat mempermudah untuk berpikir, serta anak pun merasa memiliki kesenangan tersendiri, sehingga membutuhkan pemikiran yang lebih besar dapat diasah.

Game edukasi sangat menarik untuk dikembangkan. Ada beberapa kelebihan dari game edukasi dibandingkan dengan metode edukasi konvensional. Salah satu kelebihan utama game edukasi adalah pada visualisasi dari permasalahan nyata. Game edukasi berbasis simulasi didesain untuk mensimulasikan permasalahan yang ada sehingga diperoleh ilmu yang dapat digunakan untuk menyelesaikan permasalahan tersebut. Game simulasi dengan tujuan edukasi ini dapat digunakan sebagai salah satu media edukasi yang memiliki pola pembelajaran learning by doing. Berdasarkan pola yang dimiliki oleh game tersebut, pemain dituntut untuk belajar sehingga dapat menyelesaikan permasalahan yang ada.

Dalam pemaparan di atas maka akan menerapkan Edugame "Baby Zoo Puzzle" untuk pengenalan puzzle dan mengenal binatang-binatang dalam game puzzle. Dimana pemain harus menyusun puzzle yang telah di acar posisinya dan harus menyusunnya dengan benar.

Pengunaan algoritma pengacakan posisi agar game ini lebih menarik dan tidak membosankan untuk dimainkan oleh anak, memberikan tantangan dalam menyusun potongan-potongan puzzle. Puzzle yang sudah diacak tidak dapat mudah diingat oleh pemain.

Game agent akan memberikan aksi, reaksi, mengamati, bertindak pada suatu kondisi. Sistem game agent pada permainan ini memberikan notifikasi pemberitahuan yang dibutuhkan pemain terhadap penyusunan potongan puzzle. Game agent digambarkan dengan bentuk-bentuk binatang yang memberikan pemberitahuan. Edugame merupakan salah satu model yang dirasa efektif karena tanpa sadar membuat pemain sedang bermain dan sambil belajar.

\section{RUANG LINGKUP PENELITIAN}

Dalam penelitian ini permasalahan mencakup:

1. Cakupan Permasalahan

Dari Berdasarkan latar belakang diatas, maka rumusan masalah dalam penelitian ini yaitu "Bagaimana membangun Edugame "Baby Zoo Puzzle" Berbasis Android dengan Game Agent Implementasi Finite State Machine?".

2. Batasan-batasan penelitian

Adapun batasan masalah berdasarkan penelitian diatas adalah sebagai berikut:

1) Game diperuntukkan untuk semua umur.

2) Game hanya 10 level berupa chapter atau stage yang harus dilalui oleh pemain

3) Game hanya dijalankan pada platform Android (Jellybean) dan PC

4) Untuk membuat game menggunakan SwishMax4.

5) Sistem pergerakan puzzle adalah drag and drop.

6) Content di dalam game ini tidak dapat di update secara online maupun offline

7) Game ini tidak memiliki inputan nama pemain, data pemain terakhir (history) yang bermain game ini dan tidak memiliki data tertinggi (skor akhir)

8) Game agent menerapkan metode Finite State Machine (FSM). 
9) Algoritma yang digunakan pada game ini yaitu algoritma logika pengacakan posisi yang berfungsi untuk mengacak potongan puzzle.

\section{BAHAN DAN METODE}

Adapun bahan dan metode algoritma yang digunakan dalam membangun aplikasi ini yaitu:

\subsection{Game}

Dalam kamus bahasa Indonesia game adalah permainan. Menurut Benny (2013). Game merupakan salah satu media hiburan yang popular untuk semua kalangan usia. Sejak pertama kali ditemukan sampai saat sekarang, teknologi game telah mengalami kemajuan yang terbilnag pesat. Hal ini di tandai dengan berkembangannya jenis game, produk, alat dan jenis interaksi game dengan penggunaan yang semakin beragam berbentuknya.

Menurut Zulfadli Fahrul Rozi (2010). Game atau permainan adalah sesuatu yang dapat dimainkan dengan aturan tertentu sehingga ada yang menang da nada yang kalah, niasamya dalam konteks tidak serius dengan tujuan refreshing atau hiburan.tur.

\subsection{Finite State Machine}

Pengambilan Bahasa formal dapat dipandang sebagai entitas abstrak, yaitu sekumpulan string-string simbol alphabet tertentu. Namun bahasa juga dapat dipandang sebagai entitas-entitas abstrak yang dapat dikenali atau dibangkitkan melalui suatu mesin komputasi. Mesin yang dapat mengenali bahasa kelas ini adalah Finite State Machine.

Ada beberapa definisi mengenai Finite State Machine (FSM) atau sering juga disebut dengan Finite State Automata (FSA).

1. FSM didefenisikan sebagai perangkat komputasi yang memiliki input berupa string dan output yang merupakan satu dari dua nilai yang dapat di-accept dan reject.

2. Finite Automata adalah model matematika sistem dengan masukan dan keluaran diskrit. Sistem dapat berada di salah satu dari sejumlah berhingga konfigurasi internal disebut state.

3. FSM adalah sebuah metodologi perancangan sistem kontrol yang menggambarkan tingkah laku atau prinsip kerja sistem dengan menggunakan tiga hal berikut: State (Keadaan), Event (kejadian) dan action (aksi). Sistem dapat beralih atau bertransisi menuju state lain jika mendapatkan masukan atau event tertentu, baik yang berasal dari perangkat luar atau komponen dalam sistemnya itu sendiri. Transisi keadaan ini umumnya juga disertai oleh aksi yang dilakukan oleh sistem ketika menanggapi masukan yang terjadi. Aksi yang dilakukan tersebut dapat berupa aksi yang sederhana atau melibatkan rangkaian proses yang relatif kompleks seperti pada gambar 1 .

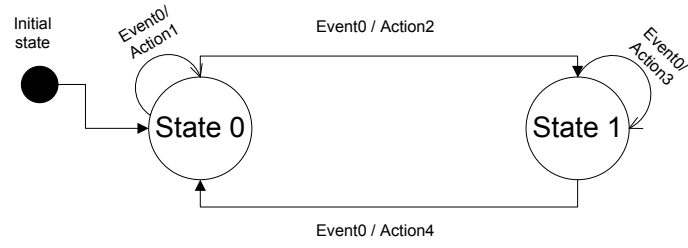

Gambar 1. Contoh diagram state sederhana.

Diagram tersebut memperlihatkan FSM dengan dua buah state dan dua buah input serta empat buah aksi output yang berbeda : seperti terlihat pada gambar, ketika sistem mulai dihidupkan, sistem akan bertransisi menuju state0, pada keadaan ini sistem akan menghasilkan Action 1 jika terjadi masukan Event0, sedangkan jika terjadi Event 1 maka Action 2 akan dieksekusi kemudian sistem selanjutnya bertransisi ke keadaan State 1 dan seterusnya.

FSM terdiri dari dua jenis, yaitu FSM ber-output dan FSM tidak ber-output. FSM tidak ber-output digunakan untuk pengenalan bahasa dalam komputer, dengan input yang dimasukkan akan diperoleh apakah input tersebut dikenal oleh bahasa komputer atau tidak. Salah satu penggunaan FSM tidak ber-output adalah program compiler, yaitu program untuk memeriksa apakah perintah yang digunakan pengguna benar atau salah. Sementara untuk FSM ber-output digunakan untuk merancang mesin atau sistem. Dan FSM yang akan digunakan dalam penelitian ini adalah FSM ber-output, dan untuk selanjutnya akan dituliskan dengan FSM saja.

\subsection{Agentt Game}

Menurut Kristanto (2005), dalam kecerdasan buatan, intelligent agentt adalah sebuah entitas otonom yang mengamati dan bertindak atas lingkungan, yaitu membutuhkan agent dan mengarahkan aktivitasnya untuk mencapai tujuan yaitu rasional. Intelligent agent juga dapat belajar atau menggunakan pengetahuan untuk mereka. Menurut nikila kasabov, agentt intelegent harus menunjukan karakteristik berikut:

1. Mengakomodasi pemecahan masalah baru aturan bertahap.

2. Beradaptasi online dan real time

3. Mampu menganalisis sendiri dalam hal perilaku, kesalahan dan kesuksesan.

4. Belajar dan meningkatkan melalui interaksi dengan lingkungan (perwujudan).

5. Belajar dengan cepat dari sejumlah besar data.

Dari karakteristik ini dapat di simpulkan bahwa agent adalah suatu fungsi terlihat seperti sendiri dalam menentukan suatu tindakan atau memberi keputusan dalam menjelankan fungsinya dalam seuah entitas otonom yang mengamati dan bertindak atas lingkungannya. 


\subsection{Puzzle}

Menurut Hidayat (2013), kata puzzle berasal dari bahasa inggris yang berarti teka-teki atau bongkar pasang, media puzzle merupkana media sederhana yang dimainkan dengan bongkar pasang.

Puzzle adalah suatu masalah dimana dapat membuat orang yang mencoba memmecahkannya berpikir. Puzzle digunakan untuk hiburan dan dapat membantu kemampuaan logika. Pemain mungkin perlu untuk mengenali pola-pola untuk mengatasinya,sehingga

mereka yang memiliki logika yang baik dengan puzzle. Bermain puzzle dapat mengasah otak kanan para pemainnya. Puzzle terdiri atas cube puzzle, Sudoku puzzle, jigsaw puzzle, dan banyak lagi.

\subsection{Android}

Menurut Safaat (2012), Android merupakan subset perangkat lunak untuk perangkat mobile yang meliputi sistem operasi, middleware dan aplikasi inti yang direlease oleh Google. Sedangkan Android SDK (Software Development Kit) menyediakan Tools dan API (Aplication Programing Interface) yang diperlukan untuk mengembangkan aplikasi pada platform Android dengan menggunakan bahasa pemrograman Java .

Dikembangkan bersama antara Google, HTC, Intel, Motorola, Qualcomm, T-Mobile, NVIDIA yang tergabung dalam $\mathrm{OHA}$ (Open Handset Alliance) dengan tujuan membuat sebuah standar terbuka untuk perangkat bergerak (mobile device).

\subsection{Tahapan Pengembangan Multimedia}

Menurut Menurut Binanto (2010), metodologi pengembangan multimedia terdiri dari enam tahap, yaitu concept (pengonsepan), design (pendesainan), meterial collecting (pengumpulan materi), assembly (pembuatan), testing (pengujian), dan distribution (pendistribusian). Keenam tahap ini tidak dapat bertukar posisi. Meskipun begitu, tahap concept memang harus menjadi hal yang pertama kali dikerjakan.

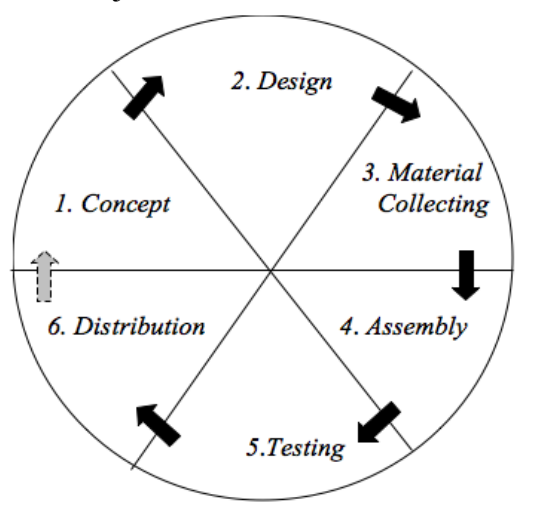

Gambar 2. Tahapan Pengembangan Multimedia

\section{Concept}

Tahapan concept (pengonsepan) adalah tahap untuk menentukan tujuan dan siapa pengguna program (indentifikasi audiens). Tujuan dan penguna akhir program berpengaruh pada nuansa multimedia sebagai pencerminan dari indentitas organisasi yang menginginkan informasi sampai pada pengguna akhir. Karakteristik pengguna termasuk kemampuan pengguna juga perlu dipertimbangkan karena dapat memengaruhi pembuatan desain.

Selain itu, tahap ini juga akan menentukan jenis aplikasi (presentasi, interaktif, dan lain-lain) dan tujuan aplikasi (hiburan, pelatihan, pembelajaran dan lain-lain). Dasar aturan untuk perancangan juga ditentukan pada tahap ini, misalnya ukuran aplikasi, target, dan lain-lain. Output dari tahap ini biasanya berupa dokumen yang bersifat naratif untuk mengungkapkan tujuan projek yang ingin dicapai.

\section{Design}

Design (perancangan) adalah tahap pembuatan spesifikasi mengenai arsitektur program, gaya, tampilan, dan kebutuhan material/bahan untuk program. Spesifikasi dibuat serinci mungkin sehingga pada tahap berikutnya, yaitu material collecting dan assembly, pengambil keputusan baru tidak diperlukan lagi, cukup menggunakan keputusan yang sudah ditentukan pada tahap ini. Meskipun demikian, pada prakteknya, pekerjaan proyek pada tahap awal masih akan sering mengalami penambahan bahan atau pengurangan bagian aplikasi, atau perubahanperubahan lain.

3. Material Collecting

Material Collecting adalah tahap pengumpulan bahan yang sesaui dengan kebutuhan yang dikerjakan. Bahan-bahan tersebut, antara lain gambar clip art, foto, animasi, video, audio, dan lain-lain yang dapat diperoleh secara geratis atau dengan pemesanan kepada pihak lain sesuai dengan rancangannya. Tahap ini dapat dikerjakan secara paralel dengan tahap assembly. Namun, pada beberapa kasus, tahap material collecting dan tahap assembly akan dikerjakan secara linear dan tidak paralel.

4. Assembly

Tahap Assembly adalah tahap pembuatan semua objek atau bahan multimedia. Pembuatan aplikasi didasarkan pada tahap design, seperti storyboard, bagan alir, dan /atau struktur navigasi.

5. Testing

Tahap Testing (pengujian) dilakukan setelah menyelesaikan tahap pembuatan (assembly) dengan menjalankan aplikasi/program dan melihatnya apakah ada kesalahan atau tidak. Tahap pertama pada tahap ini disebut tahap pengujian alpha (alpha test) yang pengujiannya dilakukan oleh pembuat atau lingkungan pembuatnya sendiri. Setelah lolos dari pengujian alpha, pengujian beta yang melibatkan penggunaan akhir akan di lakukan.

6. Distribution

Pada tahap ini, aplikasi akan disimpan dalam suatu media penyimpanan. Jika media penyimpanan tidak cukup untuk menampung aplikasinya, komprensi terhadap aplikasi tersebut akan dilakukan. Tahap ini juga dapat disebut tahap evaluasi untuk pengembangan produk yang sudah jadi supaya menjadi lebih baik. Hasil evaluasi ini dapat 
digunakan sebagai masukkan untuk tahap concept pada produk selajutnya informasi.

\subsection{Algoritma Pengacakan Posisi}

Menurut Reza Andrea, (2015), Shuffle random adalah pengacakan urutan indeks dari sebuah record atau array. Pengacakan ini diibaratkan pengocokan pada dek kartu, dimana semua kartu dikocok sehingga susunannya teracak [4]. Contoh lain misalkan A adalah array $5 \times 1$, $\mathrm{A}=\left[\begin{array}{lllll}1 & 2 & 3 & 4 & 5\end{array}\right]$ maka proses shuffle random akan mengacak susunan indek dari array A menjadi A1 $=[5$ $\left.\begin{array}{llll}1 & 3 & 2 & 4\end{array}\right]$ ataupun menjadi susunan array yang lain. Dalam bahasa pemrograman fungsi shuffle random tidak hanya dapat mengacak angka, tetapi juga dapat mengacak array string ataupun campuran string dan angka.

Untuk menerapkan pengacakan posisi gambar dengan sistem shuffle random dilakukan dengan beberapa tahap berikut ini:

1. Menentukan jumlah pasangan gambar

Awal dari penerapan yaitu menentukan jumlah puzzle pasangan gambar dan menyusunnya layaknya sebuah matrik seperti pada gambar 3 .

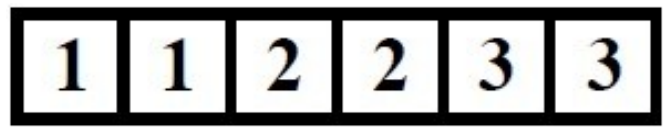

Gambar 3. Matrik 6 x 1 Permainan Match-up angka yang belum teracak

Pada tahap ini dilakukan deklarasi nilai array seperti pada contoh script dibawah ini:

$A=$ new Array $(0,1,2,3,4,5)$

Dimana nilai indeks array yang pertama (indeks ke-0) adalah 0 , dan indeks terakhir adalah 5

2. Mencatat setiap koordinat $\mathrm{x}$ dan $\mathrm{y}$ dari setiap puzzle gambar

Setiap objek gambar atau shape dalam project board permainan pasti memiliki koordinat $x$ dan $y$ seperti pada gambar 4.

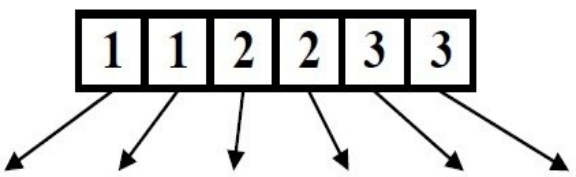

Kotak 1a Kotak 1b Kotak 2 Kotak 2b Kotak 3a Kotak 3b $\mathrm{x}=1 \overline{0} 0 \_\mathrm{x}=1 \overline{0} 0 \quad \mathrm{x}=\overline{100 \_\mathrm{x}}=\overline{100} \quad \mathrm{x}=\overline{1} 00 \quad \mathrm{x}=\overline{1}$ $\_\mathrm{y}=150 \_\mathrm{y}=200 \_\mathrm{y}=250 \_\mathrm{y}=300 \_\mathrm{y}=350 \_\mathrm{y}=400$

\section{Gambar 4. Koordinat $x$ dan $y$ dari 6 kotak gambar}

Pada tahap ini keenam koordinat kotak gambar di catat dalam sebuah prosedur

Procedure daftar_posisi()

\footnotetext{
if (posisi $=0$ ) then

$x \leftarrow 100$

$y<150$
}

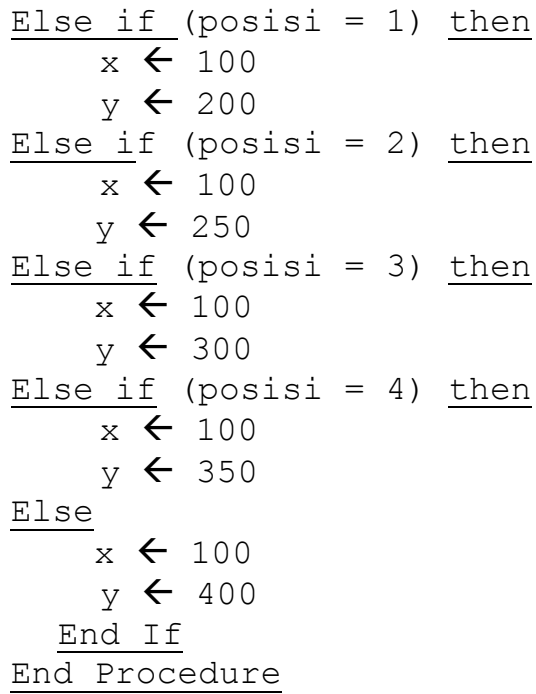

Dapat dilihat pada prosedur di atas, variabel posisi dimulai pada kondisi pada saat nilai posisi adalah 0 , nilai 0 menunjukkan nilai indek pertama dari array

3. Pengkodean pengacakan posisi

Tahap terakhir adalah penggunaan fungsi shuffle random, serta pengacakan posisi koordinat dari setiap kotak puzzle gambar, dimana setiap pasangan kotak diberi nama kotak_1, kotak_2, dan kotak_3

$A \leftarrow$ random.shuffle $(A)$

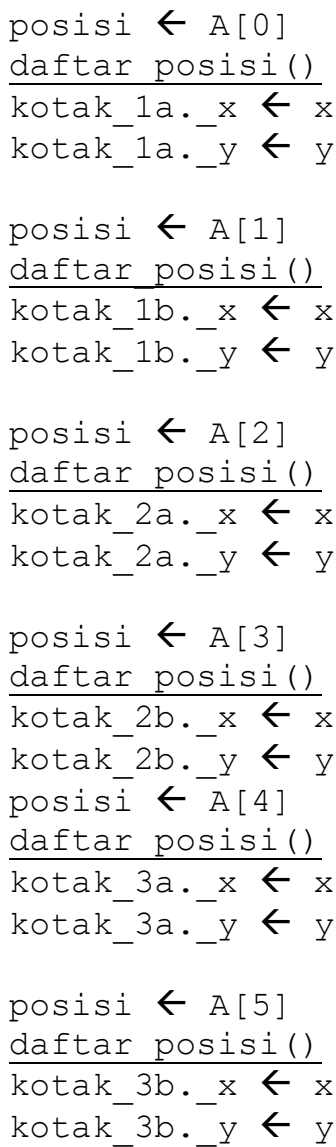

Dapat dipahami dari algoritma teks di atas, terdapat 2 kotak_1 (kotak_1a dan kotak_1b), hal ini menjelaskan 
bahwa ada 2 kotak yang memiliki gambar atau angka yang sama (ada 2 kotak bernomer 1), begitu pula pada kotak_2 dan 3.

\section{RANCANGAN SISTEM/APLIKASI}

Perancangan game agent Baby Zoo Puzzle menggunakan Unified Modeling Language (UML):

\subsection{Perancangan FSM (Finite State Machine)}

FSM adalah sebuah perancangan sistem control yang menggunakan tiga hal yaitu state, event, action. FSM ini di gunakan untuk menggambarkan tingkah laku atau prinsip kerja game agent.

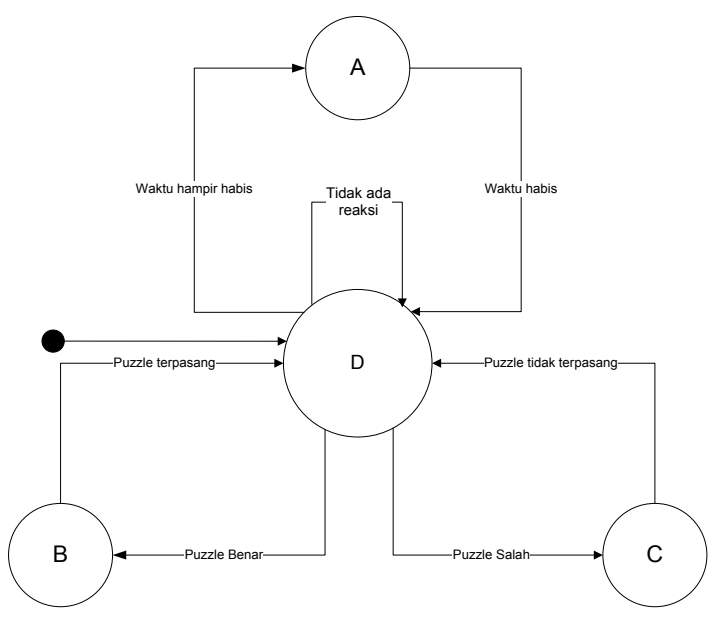

Gambar 5. Rancangan FSM (Finite State Machine).

\section{IMPLEMENTASI}

Hasil implementasi berdasarkan analisis dan perancangan adalah sebagai berikut:

\subsection{Scene Menu Utama}

Pada gambar 6 scene menu utama merupakan tampilan utama dari edugame disaat pemain baru memasuki sistem. Terdapat nama atau judul dari Edugame "Baby Zoo Puzzle". Setiap tombol pada scene menu utama memiliki fungsi masing-masing yang menghubungkan satu scene dengan scene lainnya. Tampilan scene menu utama.

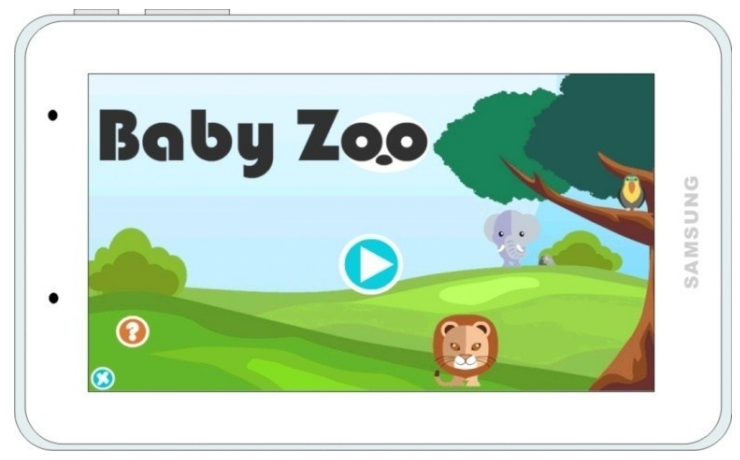

Gambar 6. Scene Menu Utama

\subsection{Scene Bermain level 1}

Pada gambar 7 Scene menu Bermain level 1 adalah Scene dimana pemain harus menyusun dan menyelsaikan permainan yang terdiri dari 4 Puzzle dengan batasan waktu bermain 25 detik.

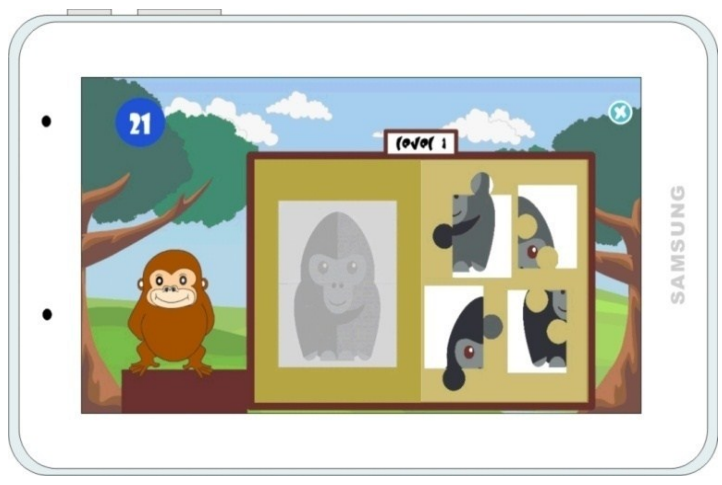

Gambar 7. Scene Bermain level 1

\subsection{Scene Menu Bermain Level 9}

Pada gambar 8 Scene menu Bermain level 9 adalah Scene dimana pemain harus menyusun gambar dan menyelsaikan permainan yang terdiri dari 16 puzzle dengan batasan waktu bermain 30 detik.

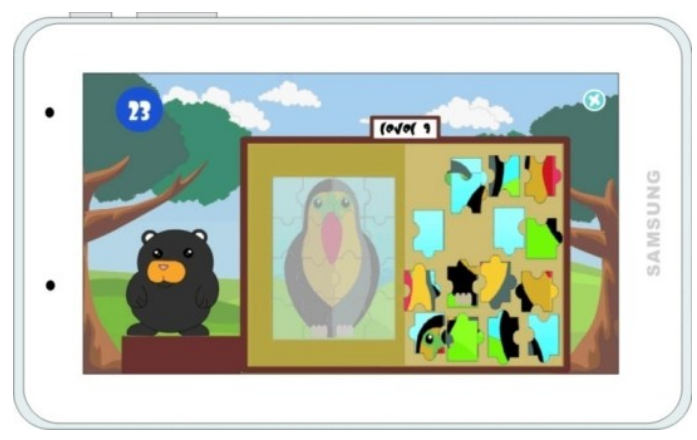

Gambar 8. Scene menu bermain level 9

\subsection{Scene Menang (Menampilkan Bintang)}

Scene mendapatkan bintang merupakan scene yang tampil disaat pemain berhasil memenangkan suatu level, pada scene ini ditampilkan skor yang diperoleh oleh pemain saat ia menyelesaikan level tersebut, jika pemain dapat menyelesaikan permainan dengan waktu yang cepat makan pemainakan memperoleh skor yang lebih tinggi. Terdapat tiga bintang pada scene untuk menggambarkan seberapa cepat pemain dapat meneyelesaikan permainan ini, pemain bisa mendapatkan 3 bintang dan sebanyak 100 skor apabila pemain dapat menyelesaikan dalam waktu 10 detik pertama dari 25 - 15 detik, pemain bisa mendapatkan 2 bintang dan skor sebanyak 75 skor apabila pemain dapat menyelesaikan permainan dalam 10 detik kedua dari 14 - 5 detik dan minimal 1 bintang banyak skor 50 apabila pemain dapat menyelesaikan dalam waktu 4 detik terakhir. Dengan kondisi yang dijelaskan sebagai berikut: if waktu $\leq 25$ Then bintang $=3$ and skor $=100$ 
Else if waktu $>26$ and waktu $\leq 35$ Then $\overline{\text { bintang }}=2$ and skor $=75$

Else Then bintang $=1$ and skor $=50$

Pada Scene ini terdapat 2 tombol utama yang memiliki fungsi masing-masing. Tombol "Lanjut" digunakan pemain untuk lanjut ke level berikutnya "Main Lagi" digunakan pemain untuk mengulang di level yang sama.Tampilan scene menang dapat dilihat pada gambar 9.

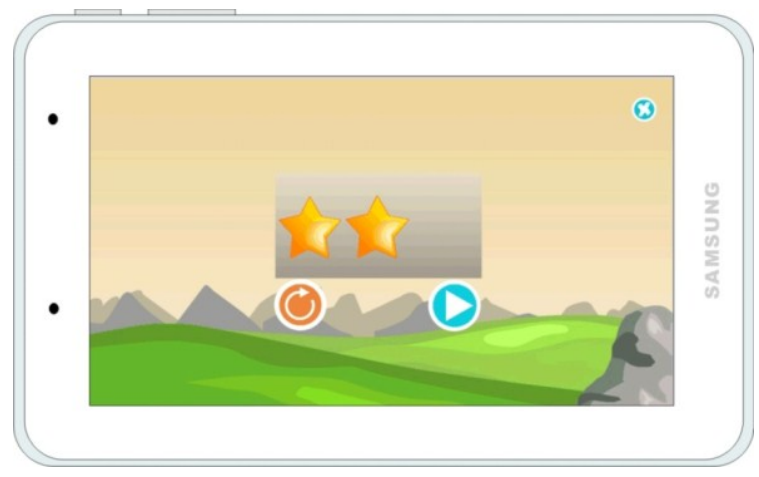

Gambar 9. Scene Menang (menampilkan bintang)

\subsection{Scene Kalah}

Pada scene kalah akan terdapat gambar karakter telah gagal menyelesaikan suatu level permainan. Pada scene ini terdapat 2 tombol utama. Tombol "try again" digunakan untuk mengulang dan mencoba kembali di level yang sama, dan tombol "home" digunakan untuk kembali ke Scene Menu .Tampilan scene kalah dapat dilihat pada gambar 10 .

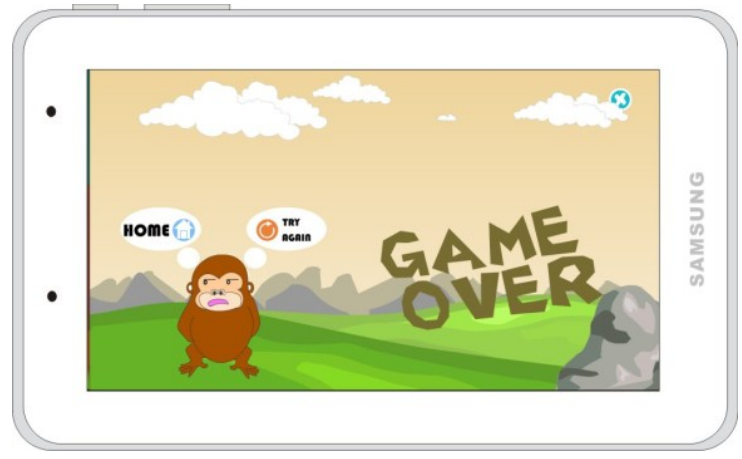

Gambar 10. Scene Kalah

\subsection{Game Agent Susunan Puzzle Benar}

Tampilan dari game agent memberikan petunjuk untuk pemain bahwa puzzle yang di susun benar.

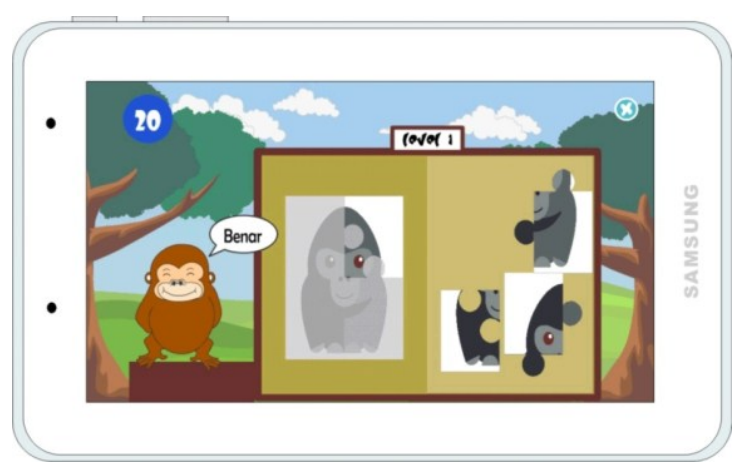

\section{Gambar 11. Tampilan dari game agent susunan puzzle benar}

\subsection{Form Hasil Perhitungan}

tampilan dari game agent meberikan petunjuk untuk pemain bahwa puzzle yang di susun salah.

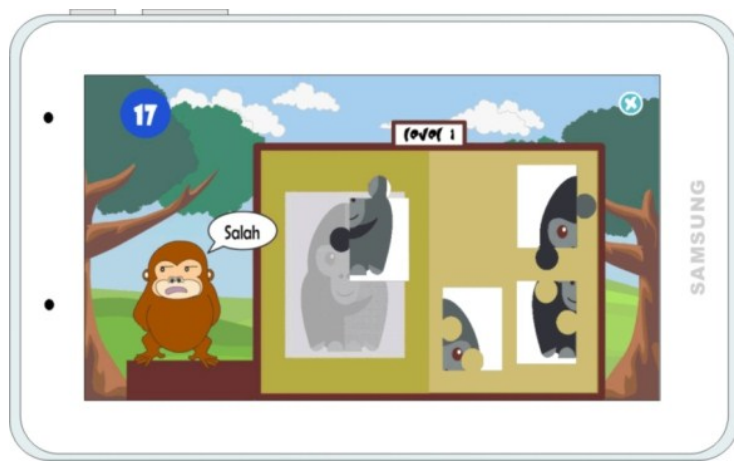

\section{Gambar 12. Tampilan dari game agent susunan puzzle salah}

\section{KESIMPULAN}

Dengan adanya hasil penelitian yang dilakukan dan Berdasarkan uraian dari masing-masing bab dan hasil pembahasan maka dapat disimpulkan bahwa Membangun Edugame "Baby Zoo Puzzle" berbasis android dengan game agent implementasi Finite State Machine sebagai berikut :

1. Pembuatan edugame "baby zoo puzzle" berbasis android melalui beberapa proses menggunakan program swishmax4 dan eclipse, setelah itu menjadi sebuah file yang dapat dimainkan di platform android dan PC.

2. Edugame "baby zoo puzzle" berbasis android dapat dimainkan untuk semua umur dari anak-anak hingga dewasa.

\section{SARAN}

Berdasarkan hasil dari penelitian ini ada beberapa saran, yaitu sebagai berikut:

1. Diperlukan perbaikan dan penambahan fitur baru agar lebih menarik.

2. Permainan ini berjalan di platform android jellybean, diharapkan game ini dapat berjalan di android kitkat dan lollipop.

3. Memperbanyak ekspresi pada game agent dan agar dapat lebih berinteraksi pada user. 


\section{DAFTAR PUSTAKA}

Adnyana, MA. 2011. Modul SwishMAx .http://ilmukomputer.org/2008/11/25/animasiflash-dengan-swishmax-2/. (Diakses pada tanggal 23 januari 2015)

Alamsyah, R.Yadi Rakhman. Nurhakim, Bhilly. Game Simulasi Pengelolaan Tanaman Di Indonesia Berbasis Desktop. Bandung : STMIK LPKIA.

Andrea, Reza, 2012, Teknik Pengacakan Posisi - Find Me The Game Prosiding Senaik 2012, Samarinda: Unmul Press.

Anung Rachman, Vincent Suhartono, Yuliman Purwanto, 2010, Agent cerdas animasi wajah untuk game tebak kata, Semarang: Universitas Dian Nuswantoro.

Binanto, Iwan, 2010, Multimedia Digital Dasar Teoridan Pengembangan, Yogyakarta: Andi.

Bambang, Warsita, 2008, Teknologi Pembelajaran dan Aplikasinya, Jakarta: Rineka Cipta.

Brownlee, J. 2011. Finite State Machine in Game. <url,http://ai-depot.com/Finite State Machine (FSM) html>. (Diakses 25 maret 2015)

Elliani. 2014. Membangun edugame Smart \& Fun Hijayah berbasis android. Skripsi S1 Teknik Informatika, Samarinda : STMIK WICIDA.

Ladjamudin, Al-bahra, 2005, Analisis dan Desain Sistem Informasi. Yogyakarta: Garaha Ilmu.

Hidayat, Febri. 2013. Perancangan game edukasi puzzle sebagai media pembelajaran untuk anaku siadini (studi kasus di tk. Pertiwi gebang-cirebon. http://elib.unikom.ac.id/. (Diakses tanggal 23 januari 2014)

Madcoms. 2008. Adobe Flash CS3 Professional, Madiun: CV ANDI OFFSET.

Madcoms, 2008, Mahir dalam 7 hari CorelDRAW X4, Yogyakarta: Andi.

Madcoms, 2005, Mahir Dalam 7 Hari Adobe Photoshop CS, Yogyakarta : Andi offset.

Nedya Matahari Bhakti. 2012. Pemetaan Perilaku NonPlayble Character Pada Permainan Berbasisi Role Playning Game Menggunakan Metode Finite State Machine, Yokyakarta.

Nugroho, Adi, 2005, Fokus Bangun Dasar Perancangan Sistem Dengan UML, Yogyakarta : Gramedia Pustaka Utama.
Pressman, Roger, 2010, Rekayasa Perangkat Lunak. Yogyakarta : Andi Offset.

Suyanto, 2005, Multimedia Alat Untuk Meningkatkan Keunggulan Multimedia, Yogyakarta: Andi.

Safaat, Nasrudin H., 2012, Pemrograman Aplikasi Mobile Smartphone dan Tablet PC berbasis Android, Yogyakarta: Andi. 